\title{
CULTURAL TRADITIONS AND ARCHITECTURAL FORM OF ITALIAN TRANSNATIONAL HOUSES IN AUSTRALIA.
}

\author{
Raffaello Furlan \\ Department of Architecture and Urban Planning \\ College of Engineering, \\ Qatar University, Doha, State of Qatar \\ raffur@gmail.com, rfurlan@qu.edu.qa
}

\begin{abstract}
The purpose of this article is to investigate the connection between cultural traditions and house form which, according to scholars, is in danger of being lost, and so contribute to the revival of critical interest in such a connection. This paper does not intend to focus on the exploration of the relation between culture as a way of life and the spatial form of the house. Instead, the main objective of this paper is to gain a deeper understanding of the nature of vernacular architecture in a precise context: this study will be focusing on the architectural form of vernacular houses built in Brisbane in the post WWII period by first generation Italian migrants, namely upon the way the house's structure, materials and construction technique, decorative feature on the façade, were influenced by migrants' cultural traditions.
\end{abstract}

Keywords: Migration; culture; way of life; cultural traditions; house form; vernacular houses; transnational houses

\section{BACKGROUND}

The literature reveals that despite buildings having been seen as an expression of people's and societies' cultural-traditional factors since the early days of civilization and the role of culture as a determinant factor in shaping the built form has also been acknowledged by modern theorists, scholars and practitioners stress that the intense complexity of human motivation that has generated architecture is being neglected in contemporary architectural design.

For example, Paul Oliver highlights how in the design of a housing project in Ghana, to be developed to allow the Gurundi and Tallensi tribes people to resettle before their lands were engulfed by a lake formed by the Volta river dam, the way of life of the inhabitants was not given much consideration. Also he stresses the need to not ignore cultures in the design of housing.

'The new housing which was designed for them was modern but I was shocked by the total lack of consideration for the existing way of life of the people.' (Oliver, 1997, p. vii).

The lack of consideration of socio-cultural factors, which had a determinant role in shaping traditional Arab settlements, has also been highlighted by Al-'Thahab, Mushatat and Abdelmomen in their study about domestic architecture of contemporary Iraq.

'It is important to investigate, analyse and study the neighbourhood unit according to the sociocultural aspects of the human in order to create a relevant social context ...' (Al-Thahab, Mushatat, \& Abdelmomem, 2014, p. 248).

The architect may design responsibly, but the process fails when he ignores the values, building skills, experience and wisdom of the cultures whose housing's needs are to be met. Housing that involves the active participation of the community, which accommodates its values, relates to its vernacular traditions while meeting its aspirations. That which retains or remains substantially as the housing of and by the people, is the housing most likely to succeed (Oliver, 2006, p. 408). 
This aspect is also emphasized by Salama (2007) who highlights that built forms should be perceived as experienced spaces, spaces which are manifestation of perceived cultural forces.

'The built environment is variant, diverse, and complex. Buildings and spaces are major components of its environment: planned, designed, analysed, represented, built, lived in and occupied. They are also experienced, perceived, and studied' (Salama, 2007, p. 112).

Oliver and Salama's argument is shared by architects Richard Rogers and David Gumuchdjjan (1996) who also argue that architecture, the multi-faceted discipline celebrated by classical theorist Vitruvius, nowadays often ignores its primordial roots which are based on cultural forces. They highlight that cause of this trend, many industrialized nations are experiencing a conflict between the need for rapid development and continuity in respecting their society's cultural traditions (Rogers \& Gumuchdjjan, 1996, p. 68).

Rogers and Gumuchdjjan (1996) stress that with so much emphasis on standards, regulations, and accountability, along with the pressures inherent in the property market whose final goal is to simply minimize building costs and maximize profit, contemporary practitioners neglect to design architectural and spatial environments responding to the users' specific needs. As a result, the contemporary trend is that buildings of all types are currently packaged and standardized, then chosen from catalogues, without any allegiance to place and society's cultural-traditions (1996, p. 68). This view is shared by Aloweid (1991) and Mahgoub (1999). Aloweid highlights how, in Saudi Arabia and the United Arab Emirates, housing construction has lost its usual image in order to fulfil specific standardization requirements. He observes that the increase of westernstyle housing was culturally inappropriate to Saudi Arabia and the United Arab Emirates. In his article 'Architecture in the United Arabs Emirates', Yasser Mahgoub, emphasizes how the development of the built form in the United Arab Emirates is entirely influenced by rapid economic changes without taking into consideration inhabitants or societal cultural-traditional factors. Also, in their exploration on socio-spatial aspects of traditional Souqs in Oman, Al-Maimani, Salama and Fadli argue that Muscat municipality should attempt to preserve and revitalize the Souq Mutrah in Muscat through a more attentive urban heritage conservation effort. Architects and urban designers are an integral component of this development process. They need to play a key role in encouraging local authorities to look into the essence of the architecture of the Souq, its evolution through people actions, and its current realities' (Al-Maimani, Salama, \& Fadli, 2014, p. 64)

Due to the need to create contemporary architectural forms responding to users' cultural traditions, social researchers and practitioners pointed out the necessity of re-evaluating a theoretical cultural framework in the architectural design of the built form (Rapoport, 1969, 1982a, 1982b, 1997, 2000). This framework is also asserted by Amos Rapoport (1969, p. 5), who undertook extensive research, dating from as early as 1969, on the relationship between built form, culture and cultural traditions, namely in a vernacular and cross-cultural context.

Rapoport's view is shared by Asquith, Vellinga (2005) and Paul Oliver (1997) who states that despite 'at the close of the 20th century, it is evident that the majority of the peoples of the world still live, works and worship in vernacular buildings' (Oliver, p. xxii), the study of vernacular architecture has been neglected in the past half century due to the interest of historians to grand or elite design.

Grand or elite building has always received a measure of attention, if only because historical works were written and read by those who built and inhabited the great houses of the past and important historical decisions were taken in them. Bu the builders of vernacular houses were in most parts of the world until the recent past very nearly illiterate. They kept few records, and the social classes which stood above them showed little interest in their lives or their lifestyles. 
The persistent neglect by formal historians of vernacular architecture is easier to explain than to excuse. The historian has traditionally been concerned with power, its locus within the state and the balance of power between states. The humbler classes have not, except on rare occasions, exercised power (Oliver, 1997, p. 46).

Both Rapoport and Oliver claimed that the interest in the way cultural traditions influence the form of domestic dwellings, the most typically vernacular building type, is frequently ignored by architects, sociologists and multi-disciplinary researchers, who are more interested in studying cultural preferences embedded in built form at a macro scale rather than a micro scale level.

Furthermore, as Rapoport states, the interrelationship of the built form and cultural traditions has not been extensively investigated in a cross-cultural vernacular housing context. In this setting, as Rapoport notes (1982a), vernacular houses built by their users in an alien built environment are referred to as 'transnational houses'. Consequently, this paper endeavours to bridge the gap between the form of houses and cultural traditions in a specific micro-scale context which is represented by vernacular houses, and to a 'setting' which is referred to as transnational houses (Poulsen \& Lange, 1998; Rapoport, 1982a). Vernacular architecture has been chosen because it is considered to be more autochthonous, spontaneous and authentic compared to that which is designed in a professional environment. Therefore, its form can be examined as evidence of the way the users influenced it in response to cultural traditions.

In this paper I will use the framework and concepts discussed by Oliver and Rapoport to investigate the way Italian migrants to Australia recreated their memory of vernacular housing in Italy for their new homes in a different country, how and the extent to which cultural traditions influenced the architectural form of Italian migrants' houses in post WWII Brisbane and the way the memory of Italian design was modified by the customs and practices of Australia.

\section{VERNACULAR AND TRANSNATIONAL HOUSES}

In this section I will provide a brief explanation of the type of building which constitutes the topic of investigation. Rapoport defines as vernacular houses (a) those artifacts built by their users within a bounded cultural and/or traditional context and (b) whose architectural forms are determined by cultural traditions learnt by the users through history and then enduring for long periods. His definition highlights the importance of understanding the active role of the (a) users in the construction of the artefact and of (b) cultural traditions as a factor determining the overall form of the vernacular house.

The vernacular house, built by the average member of the group, has certain forms which are taken for granted and strongly resist change, because some societies tend to be very tradition oriented. This justifies the relationship between built forms and culture and, furthermore, the fact that these forms endure for a very long time. In a primitive society the model is uniform being the dwellings all identical (Rapoport, 2000).

Furthermore, as stated above, Rapoport stresses the differences between vernacular and primitive built forms: he states that 'primitive buildings refers to that produced by societies defined as primitive by anthropologists, while vernacular refers to pre-industrial, modern and present-day design' (Rapoport, 1969, p. 4). Rapoport points out an aspect which is relevant to the purpose of this study: the process of construction which characterizes and differentiates primitive from vernacular architecture: while any member of the group has all the available technical knowledge to build a primitive building, in a vernacular context owners/users employ tradesmen for the construction of the building while also being participants in the design/construction process.

This definition is shared by other scholars who state that the term 'vernacular architecture' represents all buildings designed and built by their users within a bounded cultural and traditional context, in opposition to building exemplars created by formally trained architects (Al-Maimani et al., 2014; Oliver, 2006, p. 143; Smith, 2014; Tilley, Keane, Kuchler, Rowlands, \& Spyder, 2006, p. 
230). Moreover, Oliver highlights that vernacular architecture is the reflection of two components, material and cultural, of its builders and occupiers. Oliver argues that all cultures have distinctive and unique vernacular architecture traditions that are shaped by specific needs dictated by a way of life.

In his following definition Oliver highlights that vernacular architecture, developed to meet the occupiers' specific cultural needs, embodies community values and reflects both the material and cultural view of its builders and occupiers.

Vernacular architecture comprises the dwellings and all other buildings of the people. Related to their environmental contexts and available resources, they are customarily owner- or communitybuilt, utilizing traditional technologies. All forms of vernacular architecture are built to meet specific needs, accommodating the values, economies and ways of living of the cultures that produce them (Oliver, 1997, p. xxiii). To which it could be added that 'they may be adapted and developed over time as needs and circumstances change' (Oliver, 2007, p. 14).

Oliver argues that if architecture can be defined as a language form, vernacular architecture can be defined as 'the architecture language of the people' with its ethnic, regional and local dialects (Oliver, 2006, p. 17).

Finally, Rapoport and Oliver argue that history has shown how building forms cannot be understood merely by reference to climatic conditions, availability of materials, technology and biological needs. Critically, in their view materials and construction techniques can facilitate and make possible certain decisions about the form but they cannot determine or provide fully an explanation of the nature and diversity of the form to be built. It is the subtle influence of cultural forces that may affect the way people behave, and consequently the houses and settlements in which users live and the way users use them (Oliver, 2006, p. 143; 1969, p. 85; 1982a). They conclude that physical factors are treated as modifying factors rather than determinants of the form, because they do not decide what has to be built, the ways and the reasons. In their view it is the cultural concept of the house, shaped by an accepted way of doing things, acting as a factor determining the form.

The relation between the form of vernacular houses and tradition, as an accepted way of doing things, is also emphasized by Oliver who stresses that vernacular architecture is usually developed where there is a strong tradition and a supportive environment (Oliver, 1997).

Tradition and transmission consider the means by which traditions in vernacular architecture are passed on, or 'handed down' from one generation to another. Some of these are verbal, others require the training of bodily memory, but all are subject to the values and norms of the culture (Oliver, 1997, p. 70).

'Traditionally, the sensitivity and the know-how, the skills and the competence to build affectively in response the land, the climate and the resources to land, have been passed on between generations' (Oliver, 2007, p. 16).

The determinant role of cultural traditions shaping the built form is also highlighted by scholars such as Erdogan, Erkis and Smith in their analysis of the form of traditional houses located in the Sille settlement.

'Traditional house architecture and its traditional fabric constitute a live museum, which reflects history, culture, life-style and world views of a society' (Erdogan \& Erkis, 2014, p. 117).

'Housing in the two largest cities of ancient Mesoamerica -Teotihuacan and Tenochtitlanillustrates the role of cultural tradition in shaping urban house form' (Smith, 2014, p. 217)

Rapoport emphasizes the relationship between vernacular houses and variables of culture such as cultural traditions, in a context where those who create the built form have a common cultural framework with those who occupy and use the built form. This suggests that Rapoport's theory, 
applicable to a vernacular architectural context, where the resultant built forms are designed and built by the users of the built form who share a particular cultural frame, can also be applied when a migrating cultural group is involved in the creation of its own living environment while cohabiting under a different dominant framework (Miller, 1994, p. 321). As a result, Rapoport defines vernacular houses built by migrants' in a host country as transnational houses. He also highlights that trans-national houses, representing the location of most of the interaction of the members of migrant-families, adopt or change local vernacular built forms to accommodate migrants' needs and to respond to migrants' cultural frame. Therefore, as Rapoport stresses, the form of transnational houses can also be considered a physical manifestation of the culture of the users (Rapoport, 2000, p. 129).

\section{MEANINGS EMBEDDED IN THE ARCHITECTURAL FORM OF TRANSNATIONAL HOUSES}

In relation to the interpretation of the architectural form of transnational houses, in particular of the façade, for instance, Jacobs (2006, p. 180) is concerned with the relationship between migrants' past and current architectural form houses. This aspect is also highlighted by Erdogan and Erkis in their analysis of the faced of traditional houses located in the Sille settlement.

'The most distinguishing features of urban identities are houses and facades. Houses are not simply constructed within the framework of certain architectural rules. Rather, thery are designed in accordance with the user needs and they are indicators of customs and traditions narrating culture of life' (Erdogan \& Erkis, 2014, p. 119).

Through an analysis of architectural features within the current migrants' house, Jacobs shows how migrants attempt to emulate decorative elements present in their past houses with the purpose to feel at home in their new constructions and in the host country built environment. Moreover, in her study focusing on Italian migrants houses' architectural style, Baldassar (2002, pp. 84-85) highlights that Italians migrating from Treviso (San Fior) to Western Australia built the façade of their houses in Perth in the architectural style of houses built in Treviso, and therefore influenced by (1) architectural elements learnt in their native country. Borgo and Boyd showed that Italian migrants in Carlton, Melbourne, built their own houses in an 'Italian-style' and they decorated the houses with Italian statues and materials like marbles (Borgo, 2006, p. 2) (Boyd, 1987 , p. 51). Apperly, Irving and Reynolds discuss how in the 1960s Italian migrants built their houses with a distinctive style named 'Victorian Italianate' (Apperly, Irving, \& Reynolds, 1989, pp. 70-73). They state that in the 1950-60s Italian migrants purchased terrace or small Victorian and Edwardian-style cottages in inner suburbs. Afterwards the exterior and interior of these houses were renovated and modernized according to their interpretation of the way an Italian house should look like.

Exterior walls were painted with cheerful colours, porches were repaved with tiles, wrought-iron friezes were removed from the front porch and picket or wrought-iron fences were replaced with rendered concrete or exposed bricks. Columns and posts decorated the exterior, and front porches were decorated with flowers grown in pots. Pergolas were built in backyards which were usually reserved for cultivation of vegetables, grapes and olive plants. Interiors were also transformed from the dark wooden Victorian style to become light-filled and minimalist. Wooden floors were replaced with tiles or linoleum, aluminium window frames replaced timber sash windows and windows were protected with roller-shutters that were unfamiliar to local homes at that time (Azriel, 2010).

Willingham states that by the renovation of their houses in Melbourne, Italian migrants followed a 'Mediterranean Idiom'. In the quote below, he provides a description of the 'Mediterranean Idiom'.

The Mediterranean idiom or sub-style in housing in Melbourne is characterised firstly by the heavily modified facades of suburban housing in the inner suburbs, and then by the grandiose 
pseudo-Italianate villas erected on standard building lots in the outer suburbs in the late twentieth century (Willingham, 2004, p. 473).

Apperly, Irving and Reynolds also explained that in the late 1970s and early 1980s Italian migrants built their houses with the idea to express their success in a new country and also to show architectural elements they learnt from their native country. This style is defined as 'Nostalgic' (Apperly et al., 1989, pp. 270-271). A detailed portrayal of this house is explained in his quote: '[lt] was two-storied and symmetrical, with central external stair and verandah edged with bulbous Baroque balusters of precast concrete. The front elevation featured walls of buff or brown face brickwork pierced by large arched openings.'

Consequently, I argue that the architectural form of transnational houses can be interpreted in relation to previous housing experience, or as a manifestation of memory shaped through a nostalgia practice. In relation to this study, this suggests the importance to investigate the extent to which the architectural form of transnational houses was influenced by traditional architectural elements learnt by migrants through previous housing experience both in their native and host country.

Chapman (2005, pp. 18-57) emphasizes how historic evidence suggests that the human species developed with a materialistic-physical orientation: people share the need for a material world physical, tangible objects - which provides a means for people of engaging with the world on both rational and emotional levels. In this regard, Chapman refers to the numerous findings of archaeologists indicative of the prehistoric origins of material culture, such as cave paintings, tools, body adornment and other material artefacts. Objects are '...seen as an embodiment of meaning and it is from this perspective that they have to be designed'. He also states that 'even earlier versions of our present selves may have developed some form of material culture which have shaped strong emotional attachments to material possessions' $(2005$, p. 59). The reference here is to the objects that people purchase, make and use, as these have a symbolic and affective connection to the person's status. Such objects (1) serve to generate a sense of belonging to a culture that is beyond the need for survival and sustenance, and (2) are also expression of meanings and/or specific needs (Gamble, 2001, p. 101).

Csikszentmihalyi, Rochberg-Halton and Arvidsson (1981, pp. 1-24) share this view of culture: they argue that people make common sense of the world by social interaction and also by interacting with things or objects. They add that when an object has a 'meaning' to someone, then it is interpreted in the context of past experience, either consciously or unconsciously in the form of habit. The development of things in a (3) cultural tradition means that people can compare their actions with those of their ancestors. People can share common values and beliefs, or more generally culture, through interaction with objects (Arvidsson, 2006, p. 75).

These are important insights for the study of how a cultural frame extends to the way in which Italian migrants represents itself through the architectural form of their houses. These insights reveal the importance to analyse the architectural form of the house, generally as a sense of (1) belonging to a culture, (2) as expression of meanings or needs, (3) habit and traditions which people share through interaction with past housing experiences.

\section{METHODOLOGY}

In adopting a 'qualitative' methodology, this research study inevitably draws upon multiple qualitative research methods (Creswell, 2003, p. 181). One of the most significant aspects of case-study strategy is that varied methods are employed and combined, or triangulated, with the objective of exploring a case from different perspectives in order to ensure the validity of the case-study research (Denzin, 1978). This process, defined by Johansson as triangulation, or 'the combination of different levels of techniques, methods, strategies, or theories, is the essence of case-study strategy' (Johansson, 2003, p. 8). Therefore, to validate the findings within the current 
study, 'triangulation' from different sources (Yin, 2003, p. 159) is adopted. The methods employed in the research study enable the researcher to collect (1) oral data, through digitally recorded focus groups and in-depth interviews, and (2) visual data through photo elicitation, site visits, field observations and visual materials including drawings and photographs (Creswell, 2003). An integration of methods collecting both oral and visual data is considered essential for the purpose of this research study. The diagram below (See figure 1) explains the research method format.

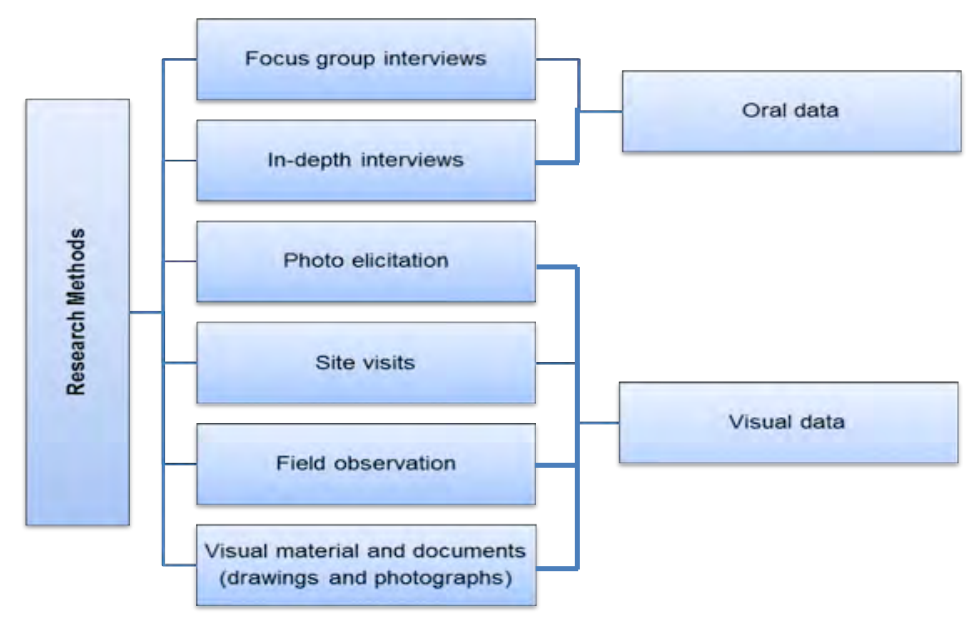

Figure 1. The research method format (Source: Author)

\section{Data collection}

The process of data collection started with the selection of Italian migrants, followed by the selection of the artifacts. The persons and the artifacts were selected according to specific criteria or limits. Interviewees were limited to migrants born in the south of Italy, given insight into Italy's cultural-traditional, regional and climatic differences, during the 1930s and 1940s. All selected first-generation migrants had migrated to Australia in the 1950s and 1960s, that is, after WWII reconstruction in Italy. As all interviewees were approximately 20-30 years old at the time of their arrival in Australia, I assume that people who lived in their homeland for several years and migrated as young adults were preferable because they had spent enough time in Italy to assimilate traditions belonging to a cultural group. Additionally, social class is a 'limit' that must also be taken into account. Pierre Bourdieu (1992) argues that domestic behavior and cultural priorities differ according to the social class people belong to. Those selected for interview can be broadly classified as working class people: they constituted the majority of Italian immigrants migrating to Australia in the post-World War II period (Cresciani, 1985, p. 95). Accounting for the limits listed above, the case study included 20 Italian migrant couples and four self-built houses which preserved their originality (Erdogan \& Erkis, 2014, p. 130). The oral and visual data were concurrently collected at different stages.

\section{Nature of questionnaire}

The hour-long interviews with the twenty couples were recorded electronically, and later thematically analysed and partly transcribed in Italian. Participants were encouraged to bring to the interview any existing photographic material that they deemed relevant that they were willing to share. At the commencement of the in-depth interview, participants talked about any photographs they brought with them. The photo-elicitation interview provided a model for collaborative research, where the interviewer would become a listener as the participants 
interpreted the images for the interviewer. This method served as an ice-breaker activity to help to create a comfortable space for discussion. The interviews began with a number of generic questions directed at the respondent's personal story about migrating to Australia, about their relationship with the neighbourhood, community, the city and their initial experience in Australia. The interviewees were then asked to provide a description of the homes in which they had lived in Italy and since their arrival in Australia. These included questions about the homes' atmosphere, and physical characteristics.

In-depth interviews with the four couples, who were chosen as cases, each of whom owned a house, took place in the participants' house and sometimes involved other family members. The interviews took around two hours on average, were digitally recorded and then were partially transcribed. Interviews were open-ended and were allowed to take the conversation to different facets of their migration experience, to tell their stories of their housing experiences, to describe their previous houses in Italy and in Australia, to draw sketches, plans and elevations of houses, and show photographs of their former houses in Italy and in Australia.

\section{Interpretations of oral and visual data}

The interpretation of personal narratives of Italians' stories gathered during the interviews was based on discourse analysis, since this method of interpreting the meaning of language, texts and visual representations, is able to 'move beyond the text, the subtext, and representation, to uncover issues of power relationships that inform what people think and do' (Waitt, 2005, p. 165). As highlighted by Azriel (2010, p. 51) the discourse is influenced by the work of the French philosopher Michel Foucault who conceived discourse within a theoretically informed framework exploring 'the rules about the production of knowledge through language (meaning) and its influence over what we do' (Waitt, 2005, p. 164).

It is also crucial to highlight the fact that the interviews were conducted in only one language, Italian. All participants delivered their stories in this language, their mother-tongue, expressing their thoughts, opinions and feelings. Having this shared native language allowed me to gain a better understanding of the ideas and feelings surrounding the home than what would have been possible for an interviewer conducting the same study in a non-native language (Vygotsky, 1978). While the exact words participants used were translated into English, the ideas and concepts conveyed originally in Italian allowed these translations to reflect a much richer understanding of the ways migrants view their homes and relate to them.

The analysis of the visual data followed the same approach as that applied to the oral data, in that it employed discourse analysis as the primary analytical tool. The aim was to analyze and interpret the visual data in a consistent manner, because visual data provided different knowledge about the way participants see the world and understand it.

The photographs taken during the site visits were used to document the interviewees' houses and to provide an important point of reference in a study that considers both the intangible ideas put forward by interviewees and the physical manifestation of these ideas when translated to the architectural features of their houses.

'In façade analysis of these houses, architectural façade elements are studied and prevalent characteristic features are identified' (Erdogan \& Erkis, 2014, p. 123)

Visual material helped in better understanding the role of cultural traditions as determining factors in shaping the architectural form of Italian migrants' houses.

\section{FINDINGS}

As already mentioned, for this study the architectural form of houses built by Italian migrants refers only to the elements characterizing the architecture of their houses: its (1) structure, (2) materials and construction techniques and (3) the decorative features visible on the main facade. 
These are the categories of the house which were analyzed. The findings summarized below will follow the categories listed above. An attempt will be made to discuss those architectural elements in Italian houses that appear to be typical and that must be explained as expression of cultural traditions, differing from other architectural creations. And a suggestion will be made where these elements were changed, to indicate the influence of Australian architectural elements.

\section{The structure}

Italian migrants pointed out that, despite the most common and spread out single storey house in Brisbane, they opted for building a spacious two storey house. Italian migrants stated that this choice was influenced by two main factors: this type of building would have allowed the users to have more space to be utilized for (a) performing specific daily activities and it would have recalled (b) the tradition of the extended family grand house in Italy (See figure 2). The large house built by migrants was the manifestation of their wish to continue in Australia the cultural tradition of the family grand-house, which traditionally was inherited by one of the heirs (See Figures 6-7-8-9).

It does not surprise their revelation that their new house in Australia was meant to represent a sort of legacy for their family and their descendants: their houses were supposed to become the new family-grand house, at least for one of their descendant, as it was in the Italian cultural tradition or as the house they lived in before departing Italy with their extended families.

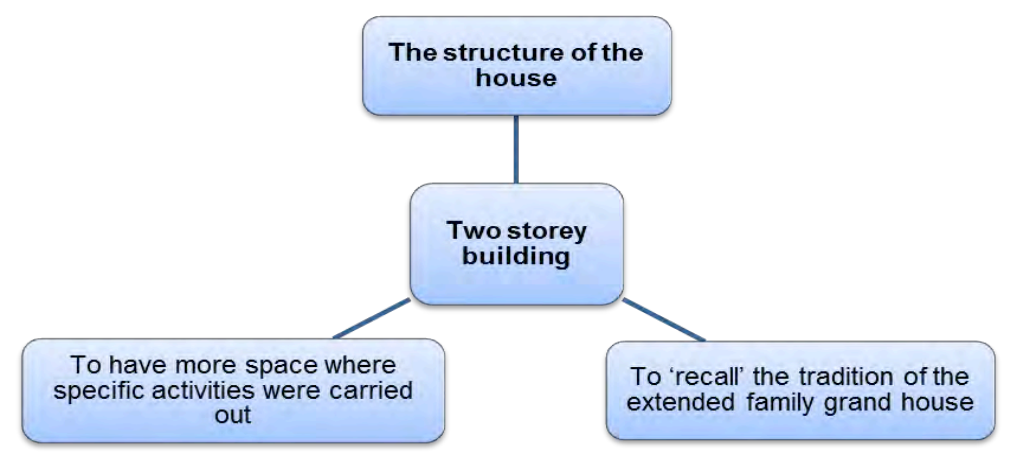

Figure 2.The Italian house's structure (Source: Author)

\section{Materials and construction technique}

In relation to materials and construction technique employed to build the house, the findings reveal that, despite the fact that most detached houses in Brisbane were built up to the 1970s by adopting two different construction systems called (a) 'weatherboard' and (b) 'brick veneer walls', Italian migrants wanted a house constructed by using a construction system called (c) 'brick cavity wall', which, as reported by the interviewees, was a technique not commonly used in the construction of dwellings in Brisbane. More specifically, the weatherboard wall consisted of the outside $20 \mathrm{~mm}$ thick horizontal weatherboard cladding, $100 \mathrm{~mm}$ air space housing the timber framing and the internal $12 \mathrm{~mm}$ thick plasterboard rendered and painted finish. The external timber boards were usually painted (See Figures 10-11). A brick cavity wall consists of two walls of $110 \mathrm{~mm}$ thick extruded bricks separated by a $50 \mathrm{~mm}$ air space. The difference between a brick veneer (Figures 12-13) and a cavity brick wall one (See Figures 14-15) is mainly in the internal wall: while in both techniques the external wall is built in bricks, the brick veneer wall has an 
internal layer consisting of a timber stud wall, while the cavity brick wall has an internal brick layer. Italian migrants and builders replaced the typical internal structural timber wall with a brick wall. Furthermore, in the case of the brick veneer wall system, the light timber slab and trussed roof are supported by the internal timber stud frame. In the case of cavity brick wall system, the internal brick wall layer supports all structural loads represented by the concrete slab and the timber trussed roof.

All interviewees stressed that the distinctive 'cavity brick' construction technique was chosen for traditional reasons, namely because Italian migrants in Brisbane were acquainted with this construction technique commonly used in Italy. Interviewees pointed out that the houses they resided in Italy before departing were traditionally constructed with the cavity brick construction system by their ancestors. Italian migrants also stressed that while in Australia some of them resided in 'weatherboard' and others in 'brick veneer wall' houses, all of them chose to build a 'brick cavity wall' house as a manifestation of physical stability, solidity, durability and thermal insulation. Therefore, cultural traditions, memory and migrants' housing experience, both in the homeland and in the host land, prior to construction of their present houses, influenced the way Italian migrants built their own houses in Brisbane (See figure 3).

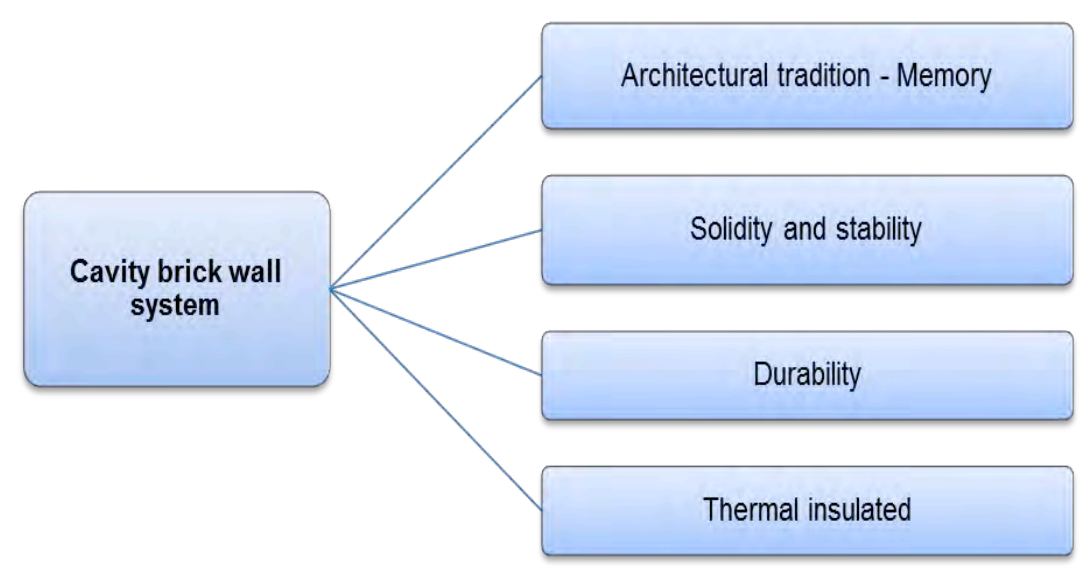

Figure 3. Cavity brick wall houses (Source: Author)

The analysis of materials and construction techniques has shown that when cultural patterns become established, there is generally a propensity to conserve them; most of the time individuals are deeply committed to their own customs. Firstly, this has been proved by the Italian migrants in Brisbane: they chose to employ the cavity brick wall system to erect the outside walls of their houses and to cast a concrete slab as a floor, as influenced by cultural tradition, or an accepted ways of doing things, memory from Italy and prestige value.

\section{The façade decorative features}

The last chosen category related to the architectural form of the house is the façade. As also envisioned by Erdogan and Erkis, 'Materials, construction technique and technology used in the traditional houses are important effects shaping the façade. Easy material, master recruitment and climate characteristics are considered in the building construction stage' (Erdogan \& Erkis, $2014, p$. 125). The material utilized to build the external walls of the house, the bricks, dictated the most common external decorative feature visible on all the façades: the face brick finish (See Figures 6-7-8-9). Italian migrants revealed that this was not a feature visible in the houses they 
lived in Italy before migrating to Australia, since Italian houses in Italy built by cavity brick walls were usually rendered and painted. Therefore, in this case they were not influenced by cultural traditions assimilated in Italy. On the other hand, they revealed that they were influenced by residing in Australia in 'brick veneer' houses where the external wall was always a face brick finish (See Figures 6-7-8-9). This wall did not require to be plastered and/or painted as it occurred in Italy, and consequently it was maintenance free.

Other features highlighted by respondents and quite evident on all the main façade of Italian migrants' houses investigated are the porch and the balcony, the brick round arches, the balustrade located on the balcony at the first floor, differentiated in stainless steel pattern or solid white concrete columns, and the Roman pillars supporting the overhanging slab on which the balustrade sits (See Figures 6-7-8-9). The first architectural element, the porch and the balcony were not recognized as elements visible in previous Italian houses: the extended family grand house presented a parallelepiped shape with no projecting volumes. On the other hand these two architectural elements were influenced by forms visible in Australian houses. The other features listed above were all influenced by architectural traditions learnt in Italy. Interviewees explicitly pointed out the reasons for having these features on the main facade: although they decided to build their houses within the Australian host built environment, they still wanted to maintain an 'Italian flavour' on the main facade through the use of architectural elements, which, in their view, are recurrent on the façade of many residential buildings in Italy (See figure 4). By utilizing traditional architectural elements visible in the built form in their native country, they wanted to create a façade reminding them of their origins. This was also proved by the fact that Italian builders, craftsmen and the owners of the house in Brisbane did not have access to any formal architectural drawings of houses built in Italy - plans, section and/or elevations - and in the end the design of the façade of their houses arose from traditions in their efforts to simulate through memory an Italian architectural design in Australia.

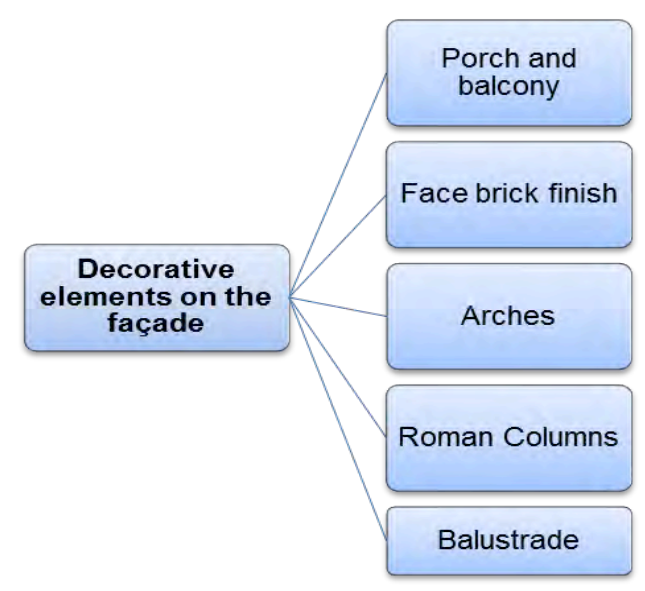

Figure 4. Decorative elements visible on the main facade

This confirmed the theories of Baldassar (2002, pp. 84-85) about traditional architectural elements used in their native country being the primary factor in influencing the façade of the transnational house. Besides, in reference to Rapoport's definition of the features characterising vernacular houses, the findings confirmed that Italian migrants worked within an idiom which they varied according to their taste. However, the lack of an aesthetical pretension, which in Rapoport's view is one of the features of a vernacular house, cannot be confirmed through this study. Italian migrants tried to express aesthetical pretension through the use of decorative architectural elements which reminded them of their traditional architectural origins. 
In addition, as pointed out earlier, distinctive features of Italian houses, represented by the porch and the balcony, were according to migrants' perspective architectural elements influenced by local architectural forms, commonly visible in Australian houses. This confirm Rapoport's view who stresses that trans-national housing is interpreted as a mix between the culture deriving from the native country and the one assimilated in the host nation.

\section{CONCLUSIONS}

At my arrival in Australia I observed the architecture of those houses built by the Italian migrants in Brisbane, but I lacked the understanding of the culture of those for whom these buildings were constructed.

The architecture of Italian migrants in Brisbane is not just about structural face brick walls and decorative round arches. The form of Italian houses in Brisbane shows more than a collection of decorative architectural elements: it is the manifestation of traditions as expression of culture of the people for whom it is built; it expresses the history of these people and of their journey, from Italy to Australia.

The findings for this research study (See figure 5) showed that the architectural form of Italian migrants' houses, namely the structure, the materials and construction technique, the decorative elements visible on the façade, were influenced by (a) cultural traditions assimilated through past housing experiences in Italy and by (b) the exposure to local architectural forms, commonly visible in Australian houses.

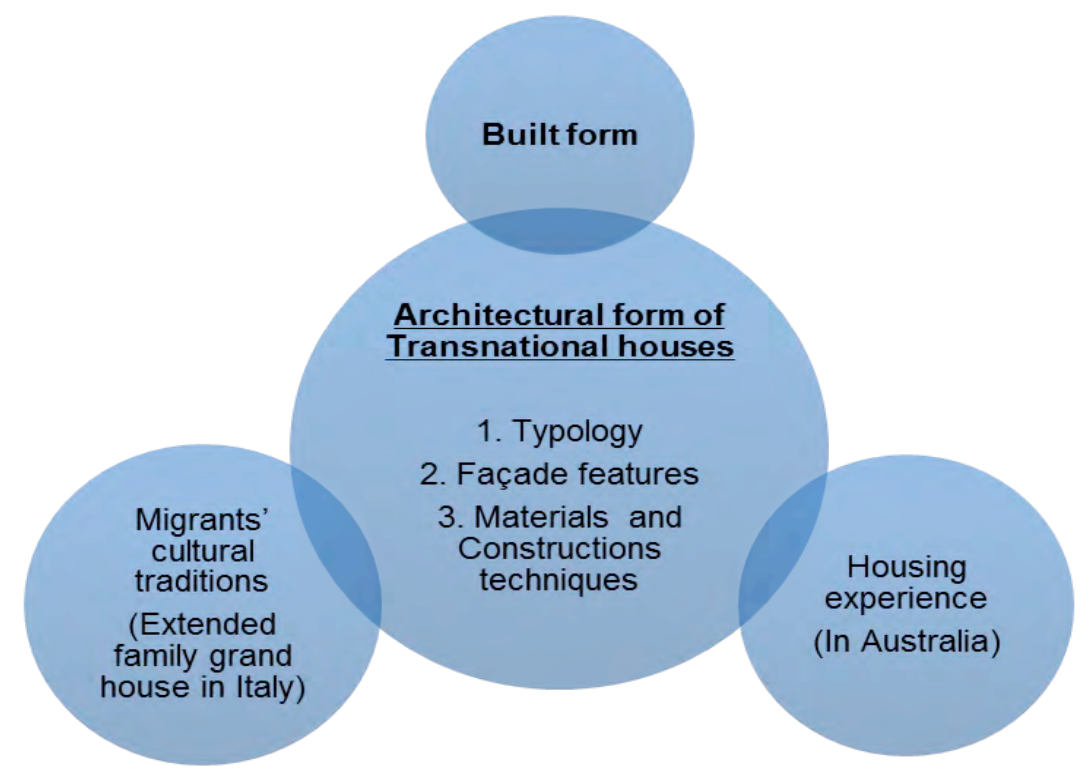

Figure 5. Findings: Factors and Influences in Italian Migrants' Houses (Source: Author)

Two conclusions might be drawn: neither tradition was ever entirely transformed; it continued to survive with only minor alterations. The architectural form as such remains, in cultural terms, a foreign element within the Australian architecture.

Finally, this study can also help in translating these research findings into practice. First, in order to support a humanistic approach, the architectural design of houses should be based upon two aims: primarily to investigate the extent to which house design can be guided by the users' 
cultural traditions; and, secondly, to investigate possible avenues of creative alternative designs for housing based on cultural traditions.

Therefore, an involvement of residents and an evaluation of responses to forms of habitation from users within a given society can improve future planning and it can progress housing process design. Such participation would enable the users to express their cultural needs and would facilitate a spontaneous, dynamic change. The culture, architectural traditions and way of life of inhabitants cannot be expressed if the environment is built through an imposed formula dictated by standardization, speculation and profit purposes. People can have a deciding role in the creation of their built form: they can put a visible imprint on it. The architectural form of houses built by Italian migrants is the manifestation of a sympathetic approach to cultural identity and its defence, in the face of off-the-shelf house design and the lack of identity that this brings.

'The main goal of conserving historical fabric and identity is to preserve an reclaim cultural heritage and to transmit them to future generations' (Erdogan \& Erkis, 2014, p. 134).

Italian migrants influenced the built form of the host Australian built environment and culture, in the form of traditions, is currently embedded in the built environment of Australia. As highlighted by Erdogan and Erkis, it is hoped that such tangible cultural heritage, which represents the national cultural heritage of Australia, is protected and transmitted to the following generations.

\section{ACKNOWLEDGEMENT}

The author thanks the anonymous reviewers for their comments, which contributed to an improvement of this paper, which is derived from the author $\mathrm{PhD}$ thesis.

\section{Appendix A: Visual Material}

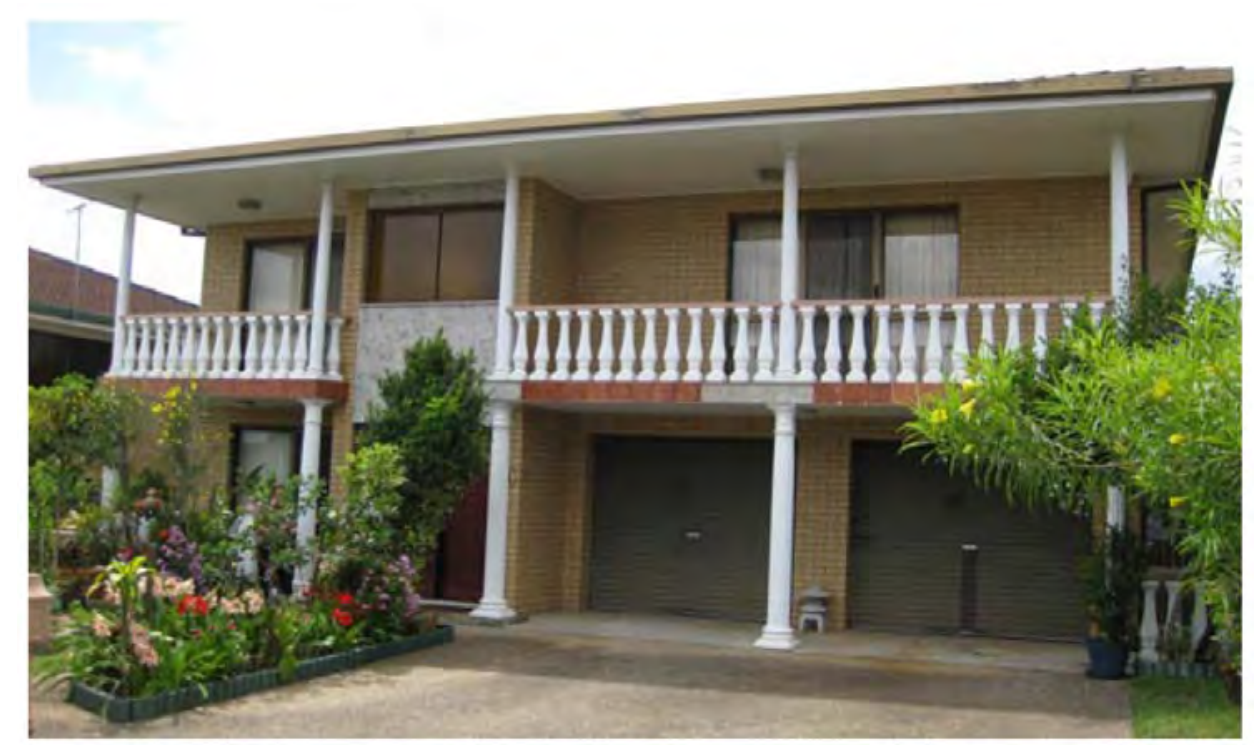

Figure 6 (Case 1). The house was built by Lina and Vittorio. The main façade is characterized by a hand made concrete balustrade and Roman columns supporting the concrete slab on the front porch (photo by the author, 2012) 


\section{$\operatorname{ArchNet} \square: \mathbf{A R}$}

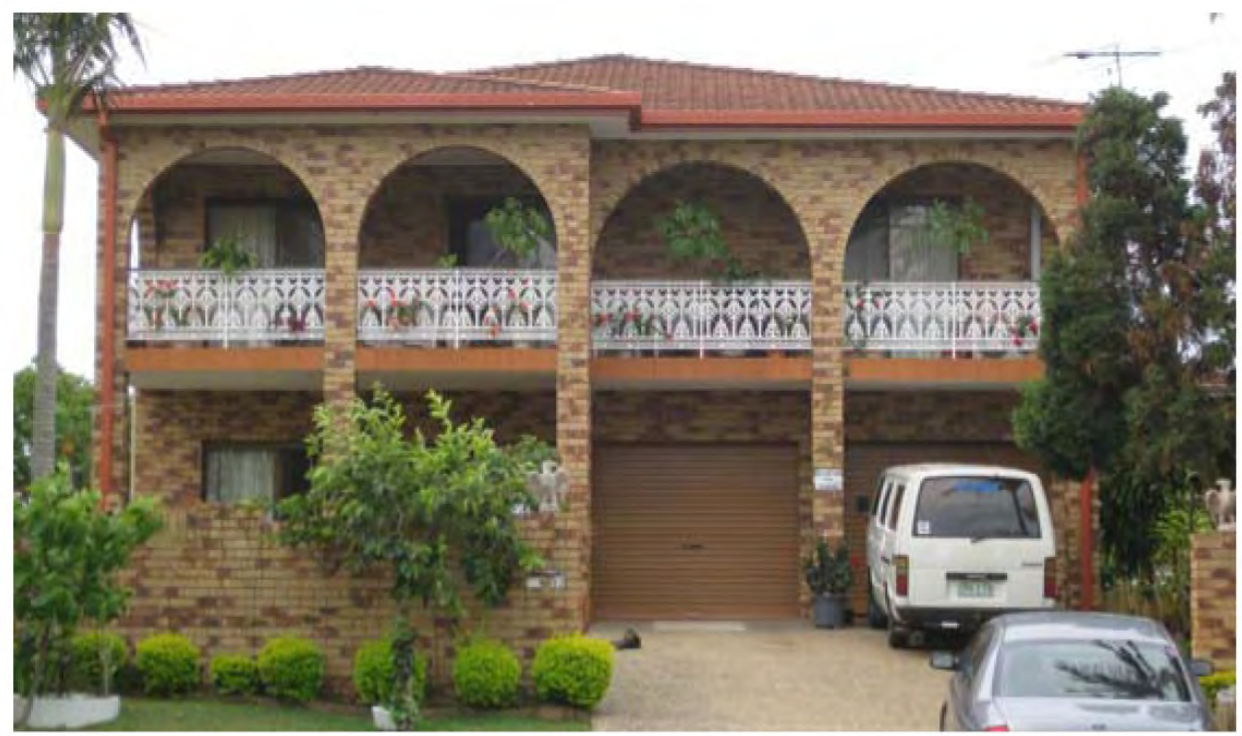

Figure 7 (Case 2). House built in 1982 by Maria and Salvatore. The main façade is characterized by a steel balustrade, brick columns supporting the concrete slab on the front porch and round arches on the balcony (photo by the author, 2012)

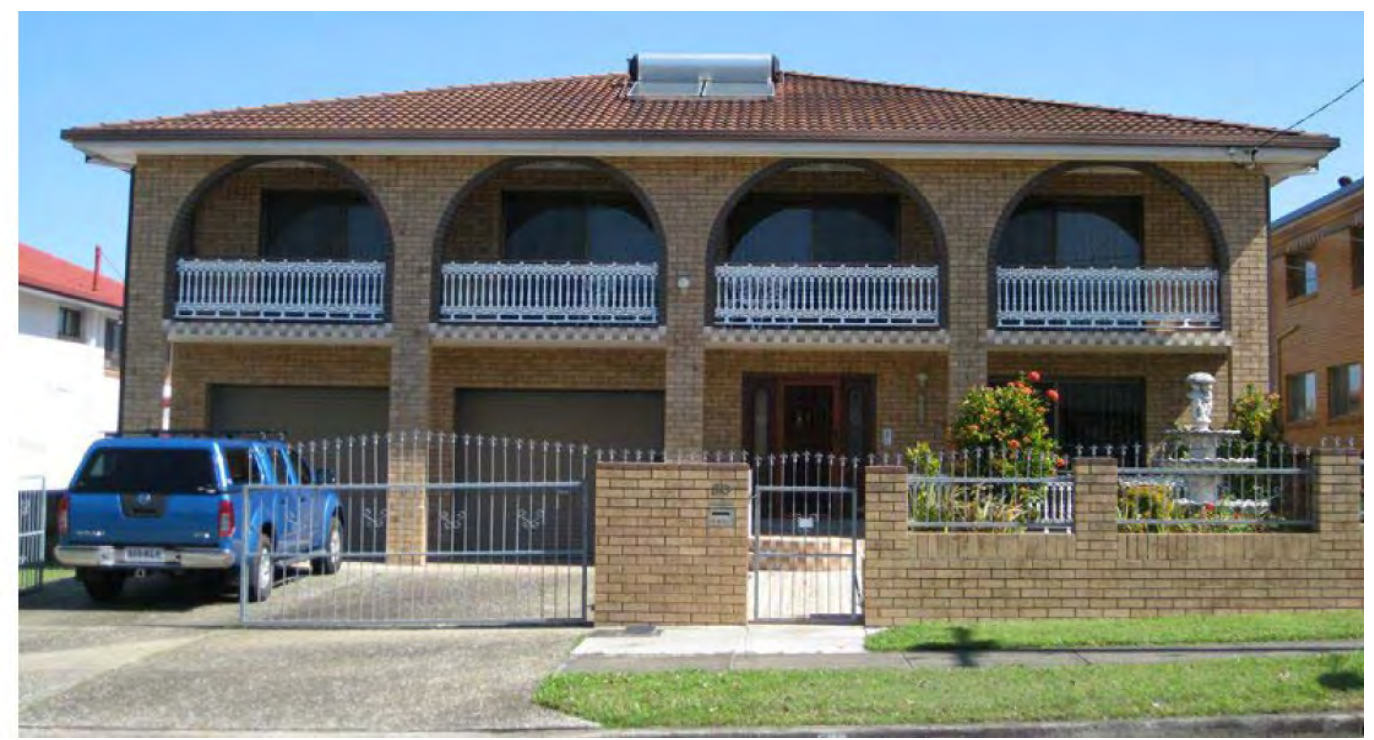

Figure 8 (Case 3). House built in 1983 by Flavia and Aldo. The main façade is characterized by a steel balustrade, brick columns supporting the concrete slab on the front porch and round arches on the balcony (photo by the author, 2012) 


\section{$\operatorname{ArchNet} \square: \mathbf{A R}$}

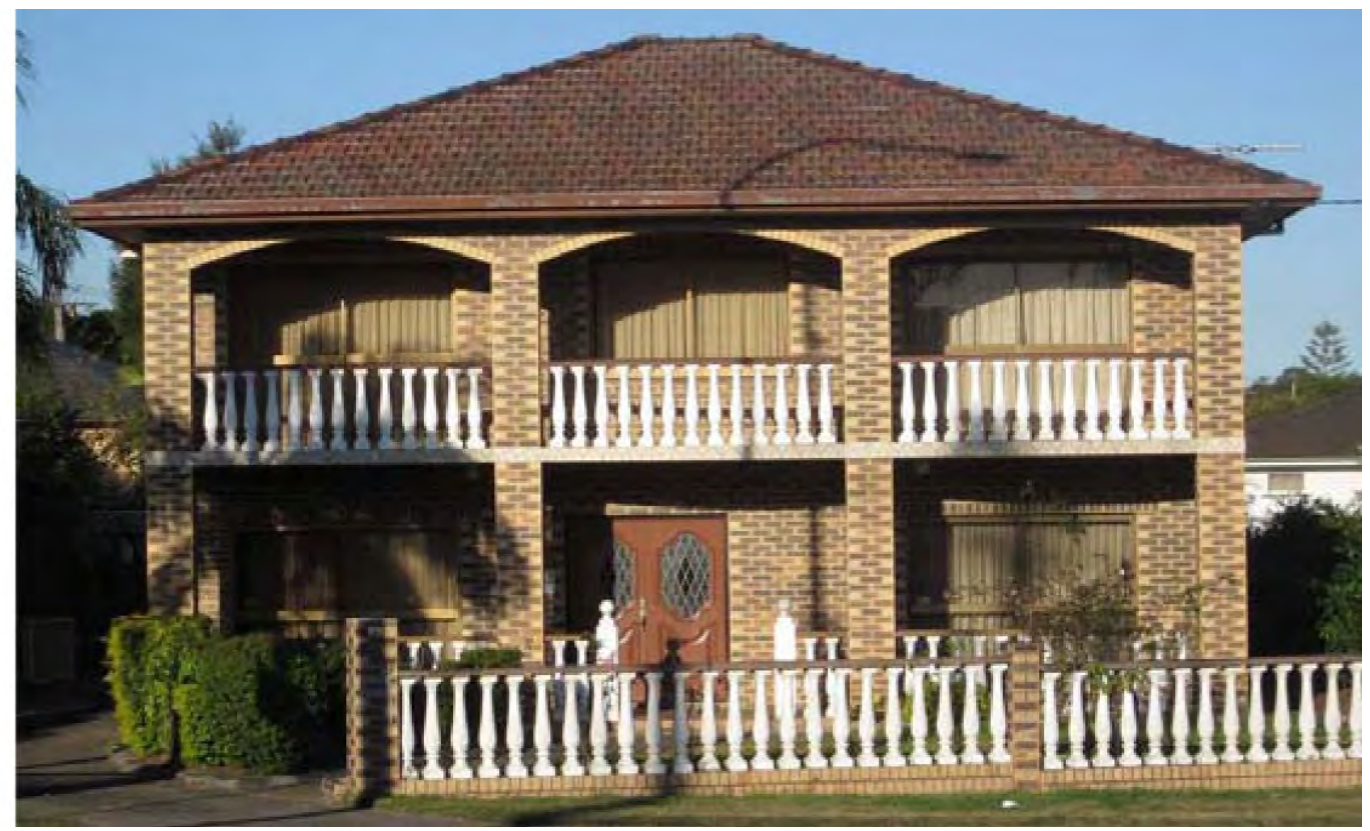

Figure 9 (Case 4). House built in 1984 by Pina and Carmelo. The main façade is characterized by a hand made concrete balustrade and brick columns supporting the concrete slab on the front porch and elliptical arches on the balcony (photo by the author, 2012)

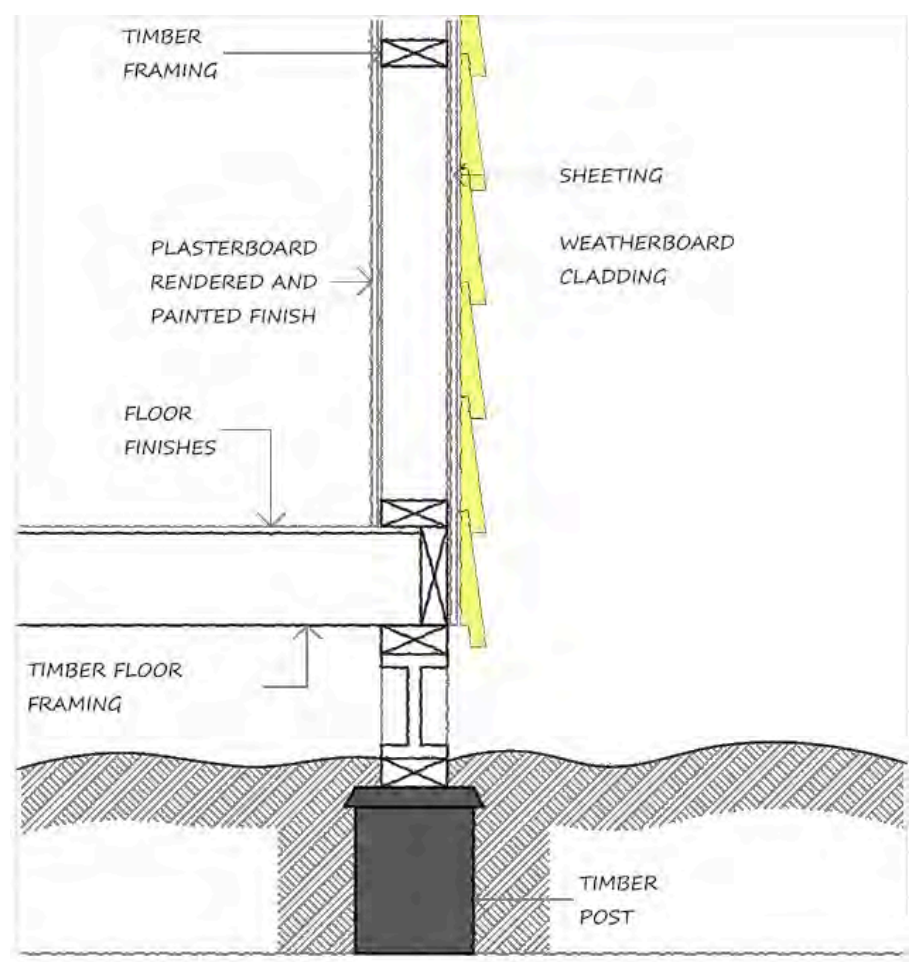

Figure 10. Schematic section of weatherboard wall (drawing by the author, 2012) 


\section{ArchNet}

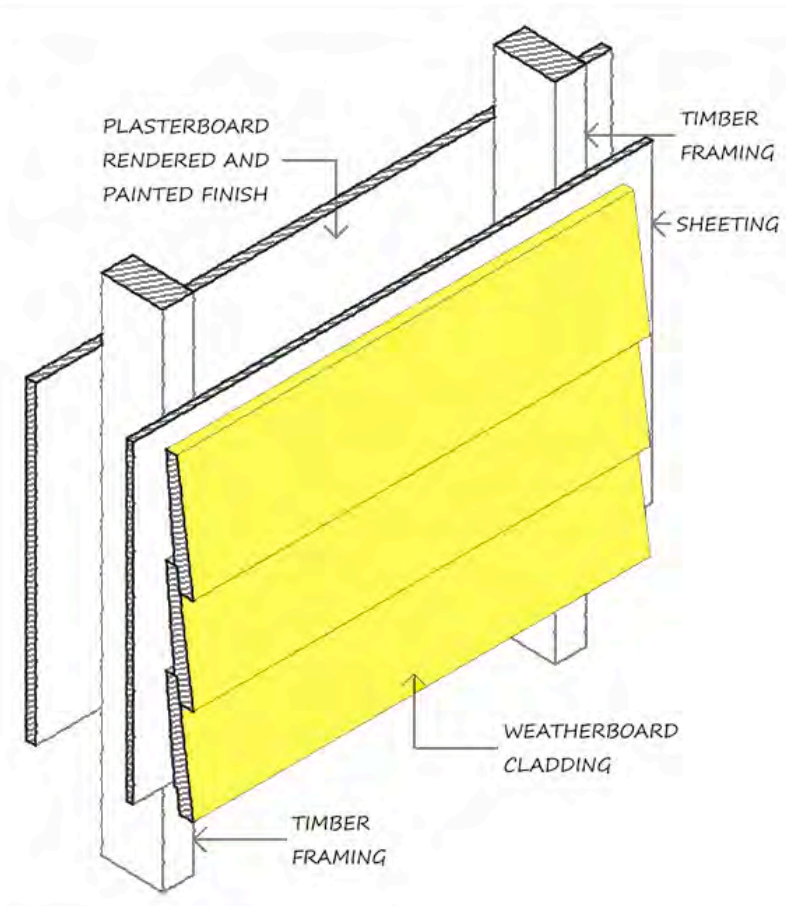

Figure 11. Schematic axonometric view of weatherboard wall (drawing by the author, 2012)

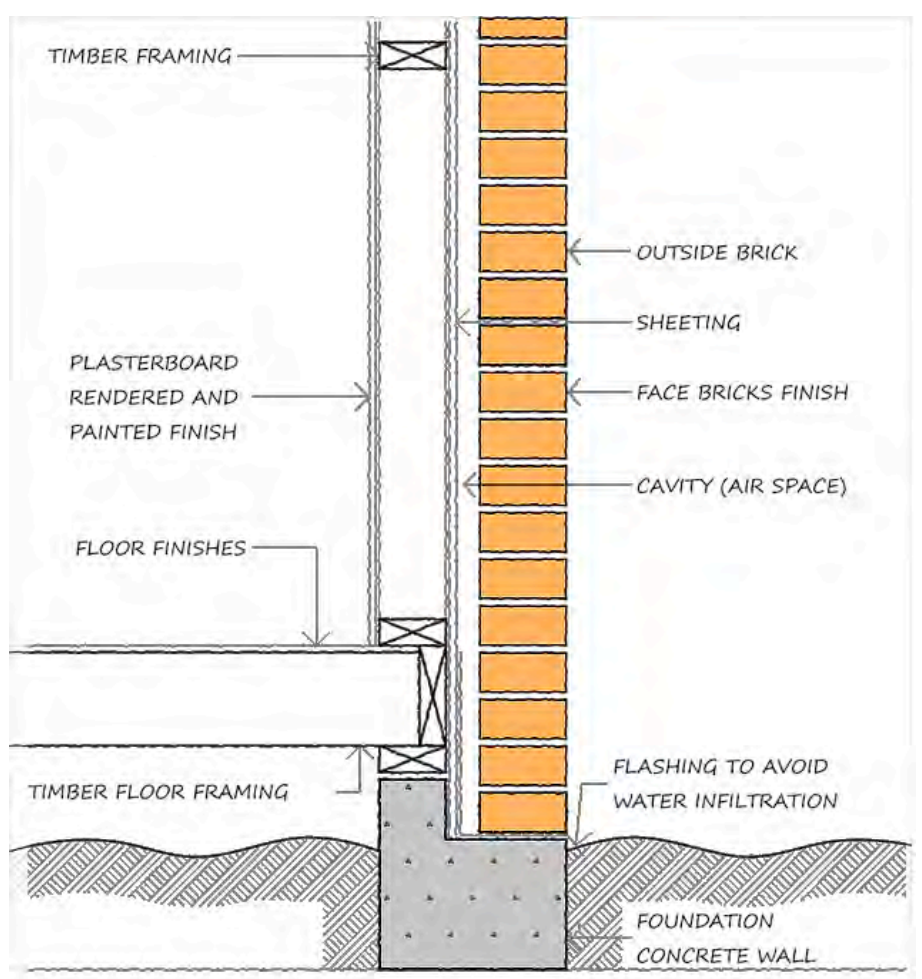

Figure 12. Schematic section of brick veneer wall (drawing by the author, 2012) 


\section{ArchNet}

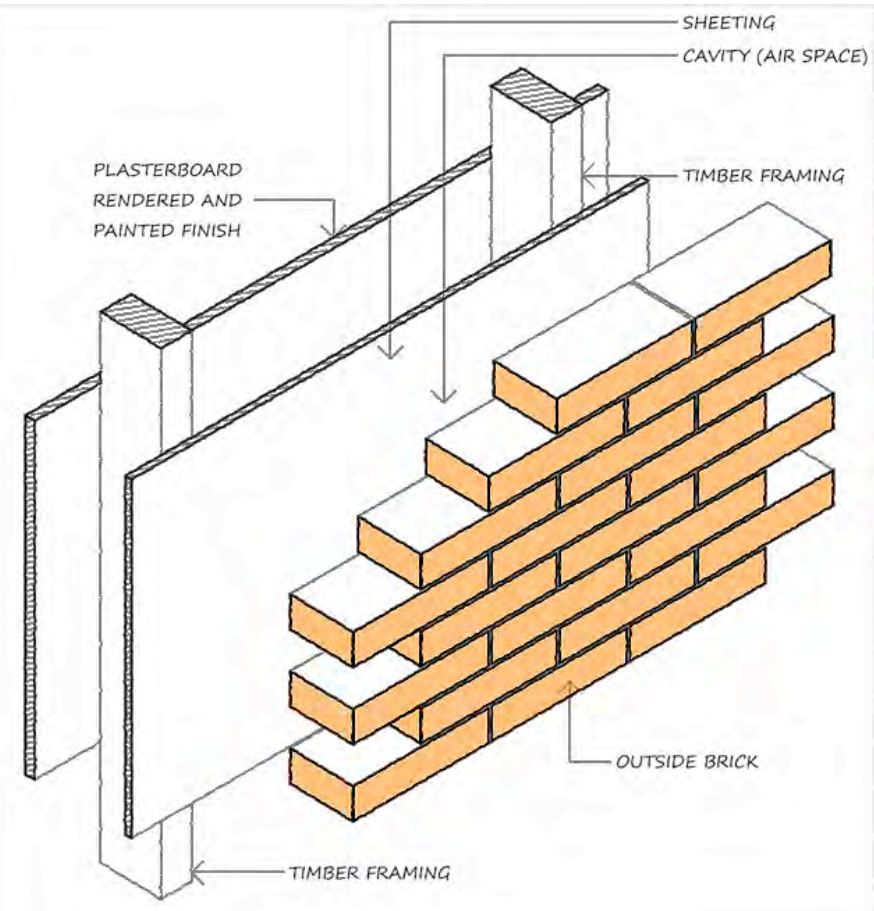

Figure 13. Schematic axonometric view of brick veneer wall (drawing by the author, 2012)

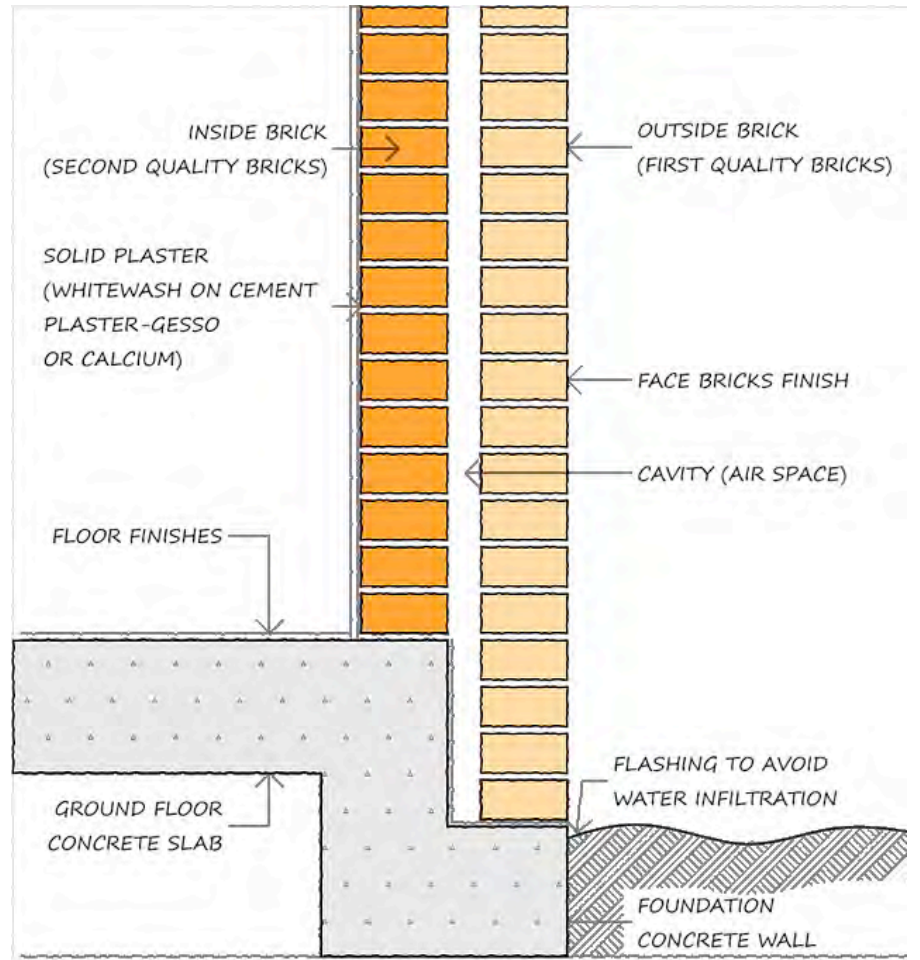

Figure 14. Schematic section of cavity brick wall (drawing by the author, 2012) 


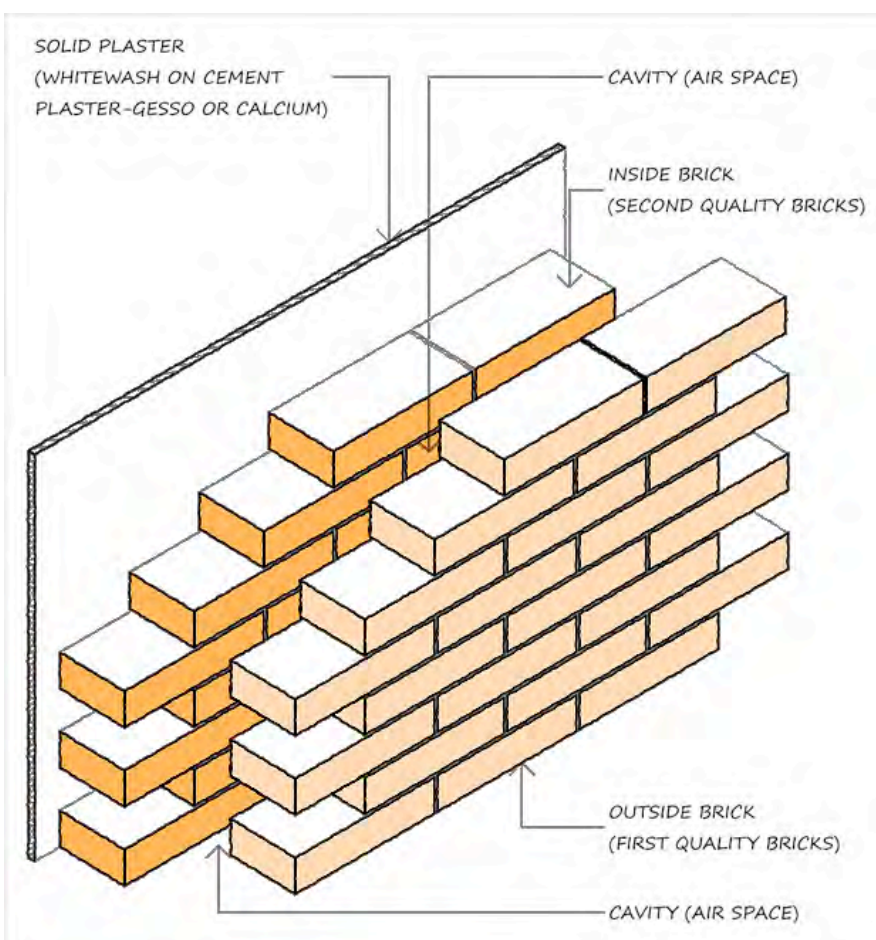

Figure 15. Schematic axonometric view of cavity brick wall (drawing by the author, 2012)

\section{REFERENCES}

Al-Maimani, A., Salama, A. M., \& Fadli, F. (2014). Exploring socio-spatial Aspects of Traditional Souqs: The Case of Souq Mutrah, Oman. Archnet-IJAR, International Journal of Architectural Research, 8(1), 50-65.

Al-Thahab, A., Mushatat, S., \& Abdelmomem, M. G. (2014). Between Tradition and Modernity: Determining Spatial Systems of Privacy in the Domestic Architecture of Contemporary Iraq. Archnet-IJAR, International Journal of Architectural Research, 8(3), 238-250.

Aloweid, A. M. (1991). An Evaluation of urban housing in The Kingdom of Saudi Arabia. Doctor of Philosophy, UQ, Brisbane.

Apperly, R., Irving, R., \& Reynolds, P. L. (1989). A Pictorial Guide to Identifying Australian Architecture: Styles and Terms from 1788 to the Present. Sydney: Angus \& Robertson.

Arvidsson, A. (2006). Brand Management and the Productivity of Consumption. In J. Brewer \& F.Trentmann (Eds.), Consuming Cultures, Global Perspectives. Historical Trajectories, Transnational Exchanges. Oxford and New York: Berg.

Asquith, L., \& Vellinga, M. (2005). Vernacular Architecture in the 21st Century: Theory, Education and Practice. London: Taylor \& Francis.

Azriel, I. L. (2010). Migrants' Houses: The Importance of Housing Form in Migrants' Settlement. Doctor of Phylosophy, The University of Melbourne, Melbourne.

Baldassar, L. (2002). Visits Home: Migration Experiences Between Italy and Australia. Melbourne: Melbourne University Press.

Blumer, H. (1969). Symbolic Interactionism: Perspective and Method. Englewood Cliffs, New Jersey: Prentice-Hall. 
Borgo, A. G. D. (2006). Signs of Italian Culture in the Urban Landscape of Carlton. Italian Historical Society Journal, 14, 2-9.

Bourdieu, P. (1992). Distinction: A Social Critique of the Judgement of Taste. London: Routledge.

Boyd, R. (1987). Australia's home: its origins, builders and occupiers. Melbourne: Melbourne University Press.

Chapman, J. (2005). Emotionally Durable Design-Objects, Experiences and Emphathy. London: Routledge.

Cresciani, G. (1985). The Italians. Parramatta Sydney: Macarthur Press.

Creswell, J. (2003). Research Design: Qualitative, Quantitative and Mixed Methods Approaches (2 ed.). Thousand Oaks, California: Sage Publications.

Csikszentmihalyi, M., \& Rochberg-Halton, E. (1981). The Meanings of Things. Cambridge, UK: Cambridge University Press.

Cuff, D. (1996). Architecture: The Story of Practice. Boston: MIT Press.

Denzin, N. K. (1978). The Research Act: A Theoretical Introduction to Sociological Methods. New York: McGraw-Hill.

Erdogan, E., \& Erkis, S. D. B. (2014). Sille Settlement in the Context of Sustainable Historical fabric and Facade Analysis of Its Traditiona Houses. Archnet-IJAR, International Journal of Architectural Research, 8(3), 117.

Gamble, C. (2001). Archaeology: The Basics. London: Routledge.

Jacobs, J. M. (2006). Too many houses for a home: Narrating the house in the Chinese diaspora. from Institute of Geography, School of Geosciences, University of Edinburgh.

Johansson, R. (2003). Case Study Methodology. Paper presented at the Methodologies in Housing Research, Stockholm.

Mahgoub, Y. (1999). Architecture in the United Arab Emirates, from http://images.google.com.au/imgres?imgurl=http://victorian.fortunecity.com/dali/428/uaearc h/Saeed5.jpg\&imgrefurl=http://victorian.fortunecity.com/dali/428/uaearch/uaearch6.htm\&h= $459 \& \mathrm{w}=556 \& \mathrm{sz}=68 \& \mathrm{hl}=\mathrm{en} \& \mathrm{start}=3 \& u m=1 \& u s g=\ldots$ KsvRxyPc_evhxnsRRuFCOGUlj0o=\&tb nid $=f X m V j L K Y u w 3 g Y M: \& t b n h=110 \&$ tbnw $=133 \&$ prev $=/$ images $\% 3 F q \% 3 D v e r n a c u l a r \% 2 B a r a$ bic\%2Bhouses\%26um\%3D1\%26hl\%3Den

Miller, D. (1994). Modernity. An Ethnographic Approach. Oxford: Berg.

Oliver, P. (1997). Encyclopedia of Vernacular Architecture of the World. New York: Cambridge University Press.

Oliver, P. (2006). Built to meet needs. Cultural Issues in Vernacular Architecture. London: Architectural Press.

Oliver, P. (2007). Dwellings: The Vernacular House World Wide. London: Phaidon.

Poulsen, M., \& Lange, A. (1998). Immigrants in Denmark. Copenhagen: Denmark Statistik.

Rapoport, A. (1969). House, Form and Culture. New Jersey: Prentice-Hall.

Rapoport, A. (1982a). Housing and Identity. Cross-Cultural Perspectives. New York: Holmes \& Meier Publishers.

Rapoport, A. (1982b). The Meaning of the Built Environment: A Nonverbal Communication Approach. Beverly Hills, California: Sage Publications. 


\section{ArchNet}

Rapoport, A. (1997). Systems of Activities and Systems of Settings. In S. Kent (Ed.), Domestic Architecture and the Use of Space: an Interdisciplinary Cross-cultural Study (pp. 9-20). Cambridge: Cambridge Univeristy Press.

Rapoport, A. (2000). Culture and built form: a reconsideration. In K. D. Moore (Ed.), Culture - Meaning Architecture: Critical Reflections on the Work of Amos Rapoport. Brookfield: Ashgate Publishing Company.

Rogers, R., \& Gumuchdjjan, P. (1996). Cities For a Small Planet. London: Faber and Faber Limited.

Salama, A. M. (2007). Contemporary Qatari Architecture as an Open Textbook. Archnet-IJAR, International Journal of Architectural Research, 1(3), 112.

Smith, M. E. (2014). Housing in Premodern Cities: Patterns of Social and Spatial Variation. Archnet-IJAR, International Journal of Architectural Research, 8(3), 207-222.

Tilley, C., Keane, W., Kuchler, S., Rowlands, M., \& Spyder, P. (2006). Handbook of Material Culture. London: Sage Publications Ltd.

Vygotsky, L. (1978). Interaction between learning and development. In M.Gauvain \& M. Cole (Eds.), Reading on the Development of Childen. New York: W.H. Freeman and Company.

Waitt, G. (2005). Doing Discourse Analysis. In I. Hay (Ed.), Qualitative Research Methods in Human Geography (pp. 163-191). Oxford: Oxford University Press.

Willingham, A. (2004). Immigrant Transformations: The Mediterranean Idiom. In P. Yule (Ed.), Carlton: A History. Melbourne: Melbourne University Press.

Yin, R. K. (2003). Case Study Research: Design and Methods. Thousand Oaks, London: New Delhi: Sage.

\section{AUTHOR}

\section{Raffaello Furlan}

Assistant Professor, PhD

Qatar University,

College of Engineering,

Department of Architecture and Urban Planning

raffur@gmail.com, rfurlan@qu.edu.qa 